\section{Minireview}

Photosynthetic Sulphate Reduction

J. D. SCHWENN

531

\section{Original Communications}

$\beta$-Carboline Alkaloids from Ribes nigrum L.

St. Blech, H. Budzikiewicz and D. Dill 540

Oxyfunctionalization of $\alpha$ - and $\beta$-Pinene by Selected Basidiomycetes

D. Busmann and R. G. Berger

545

Phylogeny and Biotransformation. Part 5: Biotransformation of Isopinocampheol

W.-R. ABRAHAM

553

Hyphodontal, a New Antifungal Inhibitor of Reverse Transcriptases from Hyphodontia sp. (Corticiaceae, Basidiomycetes)

G. Erkel, T. Anke, R. Velten, A. Gimenez and W. STEgLiCH

561

On the Mechanism of Metabolic Reactions of Amino Acids Catalyzed by Vitamin $B_{6}$ and Related Aldehydes

J. SivÝ, V. KettrmanN, J. KrätSMÁr-Šmogrovič and M. BREZA

Light-Harvesting Complexes of Aerobic Bacteriochlorophyll-Containing Bacteria Roseococcus thiosulfatophilus, RB3 and Erythromicrobium ramosum, E 5 and the Transfer of Excitation Energy from Carotenoids to Bacteriochlorophyll

V. Yurkov, N. Gad'on, A. Angerhofer and G. DREWS

579

Binuclear Manganese(III) Complexes as Electron Donors in D1/D2/Cytochrome b559 Preparations Isolated from Spinach Photosystem II Membrane Fragments

S. I. Allakhverdiev, M. S. Karacan, G. Somer, N. Karacan, E. M. Khan, S. Y. Rane, S. Padhye, V. V. KLImOV and G. RenGer
End-of-Day Light Control of Growth and Pigmentation in the Red Alga Porphyra umbilicalis (L.) Kützing

$$
\text { F. L. Figuéroa, J. Aguilera and F. X. Niell }
$$

Spermatozoid Chemotaxis in Laminaria digitata (Phaeophyceae). III. Pheromone Receptor Specificity and Threshold Concentrations

I. Maier, D. G. Müller and W. Boland 601

Impact of UV-B Radiation on the Lipid and Fatty Acid Composition of Synchronized Ditylum brightwellii (West) Grunow

G. Döhler and Th. BiermanN

607

Ionic Permeabilities of Different Isolated Fruit Cuticles Calculated by Conductivity and Membrane Potential Measurements

J. Benavente, A. Muñoz and A. Heredia 615

Phenolic Compounds in Needles of Norway Spruce Trees in Relation to Novel Forest Decline. II. Studies on Trees from Two Sites in Middle Western Germany

CH. M. Richter and A. WiLd

A Survey of Phytoalexin Induction in Leaves of the Rosaceae by Copper Ions

T. Kokubun and J. B. Harborne

628

Molecular Systematics of the Nepetoideae (Family Labiatae): Phylogenetic Implications from rbcL Gene Sequences

M. KAUfMANN and M. WINK

New Emitter-Detector-Cuvette Assembly for Measuring Modulated Chlorophyll Fluorescence of Highly Diluted Suspensions in Conjunction with the Standard PAM Fluorometer

U. SCHREIBER

646

Diethyl Phosphate Binding to Mitochondrial Cardiolipin after Intraportal Infusion in Rats

J. Schole, Chr. Schole and J. Eikemeyer 657 
Lipogenic Enzymes of Rat Liver and Adipose Tissue. Dietary Variations and Effect of Polychlorinated Biphenyls

M. Boll, L. W. D. Weber, A. Stampfl and

B. Messner

665

Modulation of Cell-Mediated Immunity by Lithium Chloride

M. Kubera, M. Bubak-Satora, V. Holan, W. Krol, A. Basta-Kaim, A. Roman, A. SkoWRON-CENDRZaK and J. SHANI

679

\section{Notes}

Two New Anthraquinones from Digitalis cariensis

S. IMre, S. ERTÜrK and Z. IMRE
Further Flavonoids and Other Phenolics of Thymus webbianus Rouy

M. A. Blázquez, S. Máñez and M. C. ZafraPolo

687

External Flavonoids of Ocotillo (Fouquieria splendens)

E. Wollenweber and G. Yatskievych 689

Stereospecific Reduction of $R(+)$-Thioctic Acid by Porcine Heart Lipoamide Dehydrogenase/ Diaphorase

H. SCHEmpp, H. Ulrich and E. F. Elstner 691

Aromatic Amino Acid and Amine Levels in the Hemolymph of Parasitized and Unparasitized Larvae of Mythimna separata

T. SHIMIzU and N. TAKEDA

693

684 Erratum

696 


\title{
The Impairment of the Nodulation Process, Induced by a Bradyrhizobium japonicum Exopolysaccharide Mutant is Determined by the Genotype of the Host Plant
}

\author{
Kerstin Kosch ${ }^{\mathrm{a}}$, Andreas Jacobia ${ }^{\mathrm{a}}$, Martin Parniske ${ }^{\mathrm{b}}$, \\ Dietrich Werner ${ }^{\mathrm{a}}$ and Peter Müller ${ }^{\mathrm{a}}$ \\ ${ }^{a}$ Fachbereich Biologie, Botanisches Institut der Philipps-Universität, \\ Karl-von-Frisch-Straße, D-35032 Marburg/Lahn, Bundesrepublik Deutschland \\ b Max-Planck-Institut für Züchtungsforschung, Carl-von Linné-Weg 10, \\ D-50829 Köln, Bundesrepublik Deutschland
}

Z. Naturforsch. 49 c, 727-736 (1994); received August 3, 1994

Bradyrhizobium, Exopolysaccharides, Nodulation, Determinate Nodule Type, Soybean

The deletion mutant Bradyrhizobium japonicum $\triangle \mathrm{P} 22$ produces a structurally altered exopolysaccharide. The nodulation of two cultivars each of Glycine max and Glycine soja, and cultivars of Macroptilium atropurpureum and Vigna radiata, infected with this mutant was examined in order to analyze the role of the exopolysaccharide in the infection process of plants with a determinate nodule type. All host plants analyzed exhibited delayed nodulation and formed fewer nodules per plant. The extent of the impairments depended on the genotype of the host plant. Morphological studies confirmed these results. In $V$. radiata later steps in nodule development proceeded without further disturbances, whereas with $G$. soja PI 407287 minor changes were detected. In contrast, the inoculation of G. soja PI 468397 and $M$. atropurpureum lead to the formation of nodules most of which were not infected by Bradyrhizobium japonicum $\Delta \mathrm{P} 22\left(\mathrm{Inf}^{-}\right)$. However, on $M$. atropurpureum at least some effective nitrogen-fixing nodules developed. Such nodules did not emerge from G. soja PI 468397. Inf $^{-}$nodules were arrested in an early stage of nodule development, and symptoms of plant defense responses were observed.

\section{Introduction}

Inoculation of legumes with gram-negative soil bacteria of the genera Rhizobium/Bradyrhizobium and Azorhizobium leads to the formation of a new symbiosis-specific organ, the root nodule. The nodule provides a microaerobic habitat where the bacteria are able to fix atmospheric dinitrogen. The development of this symbiosis requires a bidirectional molecular communication. In the early stage of this interaction the host plant exudes flavonoid compounds which stimulate the expression of the nod genes (Peters et al., 1986). The nod genes in turn encode enzymes involved in synthesis of the nod factors, lipooligosaccharide signal molecules that cause symbiosis-specific changes in the plant root (Lerouge et al., 1990; Fisher and Long, 1992; Göttfert, 1993).

Abbreviations: dpi, days past infection; EPS, exopolysaccharide; nfw, nodule fresh weight; HR, hypersensitive reaction; LPS, lipopolysaccharide; rtm, root tip mark.

Reprint requests to Dr. P. Müller.

Telefax: 49 (6421) 282057.
In search of other signal molecules that play a significant role in the symbiotic interaction surface polysaccharides like exopolysaccharides (EPS) and lipopolysaccharides (LPS) have been found to be essential for the establishment of an effective symbiosis (Finan et al., 1985; Leigh et al., 1987; Müller et al., 1988; Stacey et al., 1991). Inoculation of alfalfa which produces indeterminate nodules with Rhizobium meliloti EPS mutants results in the induction of nodule-like organs; nevertheless, the central nodule tissue is not invaded by the bacteria (Inf- phenotype). A similar phenotype was observed with B. japonicum LPS mutants in combination with plants of the determinate nodule type (Stacey et al., 1991). However, the inoculation of the latter plants with EPS mutants leads to the establishment of an effective nitrogen-fixing symbiosis, indicating that intact EPS is not essential for the symbiosis with determinate type legumes (Diebold and Noel, 1989; Hotter and Scott, 1991).

As previously reported the nodulation of G. max "Preston" and G. soja PI468397 is impaired in an early developmental stage when in- 
oculated with the exopolysaccharide mutant B. japonicum $\triangle \mathrm{P} 22$, which produces an EPS of an altered structure. Furthermore, plant defense reactions were detected (Parniske et al., 1993; Parniske et al., 1994). The present report shows that inoculation with this EPS mutant can lead to an $\mathrm{Inf}^{-}$ phenotype on determinate nodule type plants and that the degree of the impairment mainly depends on the genotype of the host plant.

\section{Materials and Methods}

\section{Plant material and inoculum strains}

Glycine max "Preston" and "Maple Arrow" seeds were obtained from Pioneer Hi-bred Inc., U.S.A. and Ottawa Research Station, Canada, respectively. Glycine soja PI468397 and PI 407287 seeds were a gift from P. B. Cregan, Beltsville, U.S.A. Macroptilium atropurpureum seeds were generously given by S. Crank, Wye College, London, U.K. Vigna radiata seeds were obtained from a local source.

The wild type strain was Bradyrhizobium japonicum 110spc4 (Regensburger and Hennecke, 1983). The construction of the mutant strain Bradyrhizobium japonicum $\triangle \mathrm{P} 22$ was described elsewhere (Parniske et al., 1993). Rhizobial strains were grown at $28^{\circ} \mathrm{C}$ in a mineral medium with succinate (SMM) as the sole carbon source (Schmidt et al., 1992).

\section{Plant growth and inoculation}

Seeds were surface-sterilized by immersion in $30 \% \mathrm{H}_{2} \mathrm{O}_{2}$ for $15 \mathrm{~min}$, washed ten times with sterile water, imbibed $6 \mathrm{~h}$ in sterile water and washed again. Seeds were pregerminated for 3 days at $28^{\circ} \mathrm{C}$ in the dark on nitrogen-free nutrient agar (Werner et al., 1975). Seeds of G. soja PI 468397 were scarified prior to germination. After 3 days the seedling roots were submersed in a suspension containing $10^{6}$ bacteria $\times \mathrm{ml}^{-1}$ for $30 \mathrm{~min}$ and were then transferred into growth pouches with $10^{6}$ bacteria per plant in $20 \mathrm{ml}$. The location of the root tip was marked. The plants were grown in a growth chamber at a constant temperature of $25^{\circ} \mathrm{C}, 75 \%$ relative humidity, and a day/night regime of $16 / 8 \mathrm{~h}$ with a light intensity of $2550 \mu \mathrm{E} \times \mathrm{m}^{-2} \times \mathrm{s}^{-1}$. Every two days $20 \mathrm{ml}$ nitrogen-free nutrient solution were added. At $21 \mathrm{dpi}$, the plants were harvested.

\section{Acetylene reduction assay}

Acetylene reduction assays of cut root systems in glass tubes were performed according to Koch and Evans (1966).

Fixation, embedding and microtomy of the nodules and staining of the sections

For embedding in L. R. White (London Resin Co.) nodules were harvested 21 days after inoculation, cut with a razor blade and fixed in $2 \%$ glutaraldehyde in $50 \mathrm{~mm}$ potassium phosphate buffer, pH 6.8, for 1 or $2 \mathrm{~h}$ under vacuum. After washing in buffer the nodules were dehydrated in a graded ethanol series, left over night in L. R. White: ethanol $1: 1(\mathrm{v} / \mathrm{v})$, and finally infiltrated in L. R. White. Polymerization was performed with $1 \%$ enhancer at room temperature. Semithin sections of about $1 \mu \mathrm{m}$ were cut with an OM U 2 Reichert microtome equipped with a Ralph glassknife. Sections were stained for $90 \mathrm{sec}$ at $60^{\circ} \mathrm{C}$ with Toluidineblue $\mathrm{O}(1 \%$, w/v, Toluidineblue $\mathrm{O}$

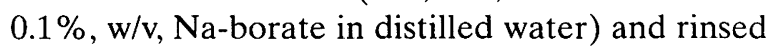
with warm tap water. The slides were viewed by light microscopy (Orthoplan, Leitz) and for the occurrence of autofluorescence with a Leitz Laborlux fluorescence microscope (excitation filter $270-380 \mathrm{~nm}$, barrier filter $510-580 \mathrm{~nm}$ ).

\section{Results}

\section{Delay of nodulation}

The organogenesis of leguminous root nodules follows a certain developmental program under defined cultural conditions. Less adapted combinations of host plant and inoculum strains result in a delayed onset of nodulation, which has also been found for deletion mutants of Bradyrhizobium japonicum defective in EPS synthesis (Parniske et al., 1993). Inoculation with B. japonicum $\triangle \mathrm{P} 22$ led to a delay of nodule development for all host plants tested. Visible nodule primordia appeared three to four days later than on wild typeinoculated plants. Infection of rhizobia in roots of leguminous host plants occurs via young or just developing root hairs which are located in a short distance above the root tip at the time of inoculation (Bhuvaneswari et al., 1980). Therefore, a quantitative method to determine the time course of nodule induction is to measure the distance of 
the uppermost nodule to the root tip of the main root at the time of inoculation. The uppermost nodule induced by the wild type $B$. japonicum $110 s p c 4$ is located just above or below the root tip mark (Fig. 1). The distance from the uppermost nodule to the root tip mark ( $\mathrm{rtm}$ ) was greater in all cases when the EPS-deficient mutant B. japonicum $\triangle \mathrm{P} 22$ was inoculated to the plants (Fig. 1). This effect was most pronounced with Vigna radiata. No nodules developed at the main root, although fewer nodules on the main root of this host plant were generally induced by the wild type (Table I). The phenomenon of impaired nodulation was further confined by the observation that in all plant species tested, the number of plants nodulated at the main roots was reduced and the proportion of nodules at the main root was decreased.

Inoculation of Glycine soja PI 468397 with B. japonicum $\triangle \mathrm{P} 22$ resulted in the formation of tissue

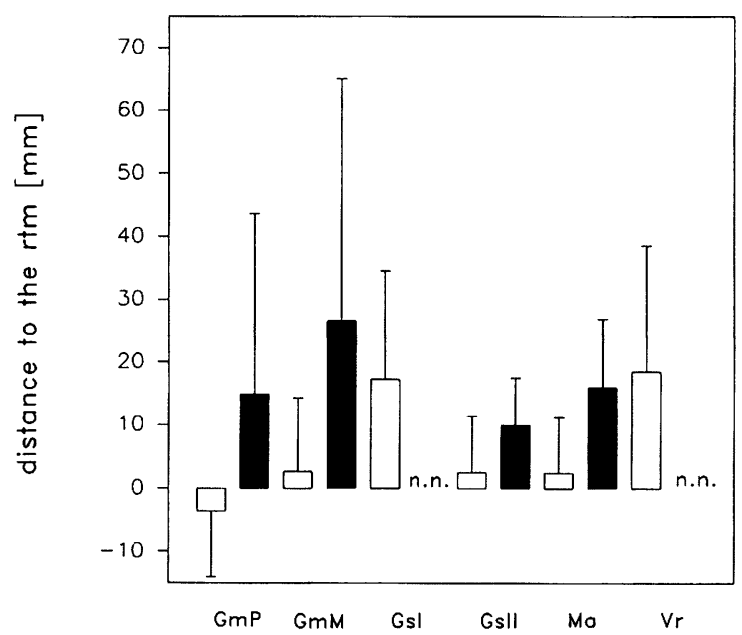

Fig. 1. Distance of the uppermost nodule to the root tip mark ( $\mathrm{rtm})$, of the main root at the time of inoculation of different host plants inoculated with $B$. japonicum 110 spc 4 (white bars) and $B$. japonicum $\triangle \mathrm{P} 22$ (black bars). Negative values indicate a position above the $\mathrm{rtm}$ directed to the shoot, positive values a position below the $\mathrm{rtm}$ directed to the root tip. The data represent the average (with standard deviation) of three independent experiments (T-test, number of plants $n>17, p<0.05$ ). Differences were significant for all host plants (GmP, Glycine max "Preston"; GmM, Glycine max "Maple Arrow"; GsI, Glycine soja PI468397; GsII, Glycine soja PI 407287; Ma, Macroptilium atropurpureum; Vr, Vigna radiata; n.n. no nodules at the main root. The tissue protrusions of $G$. soja PI 468397 were not regarded as nodules in these experiments). protrusions which almost exclusively emerged at the sites of lateral root development. These were not regarded as nodules because macroscopically they resembled undifferentiated cell clusters.

\section{Reduced nodule number per plant and effectivity of the mutant nodules}

Another indication for the disturbed nodulation process following the inoculation with $B$. japonicum $\triangle \mathrm{P} 22$ was the reduced total number of nodules per plant compared to wild type-infected plants (Fig. 2). Again the most pronounced phenotype was observed with Vigna radiata and the noninfected G. soja PI 468397, whilst G. soja PI 407287 was less affected. The decrease in the total number of nodules per plant was greater in G. max "Maple Arrow" than with "Preston".

In order to analyze the effectiveness of the symbiosis with $B$. japonicum $\Delta \mathrm{P} 22$, specific nitrogenase activity was measured by the acetylene reduction assay (Fig. 3). Mutant and wild type-

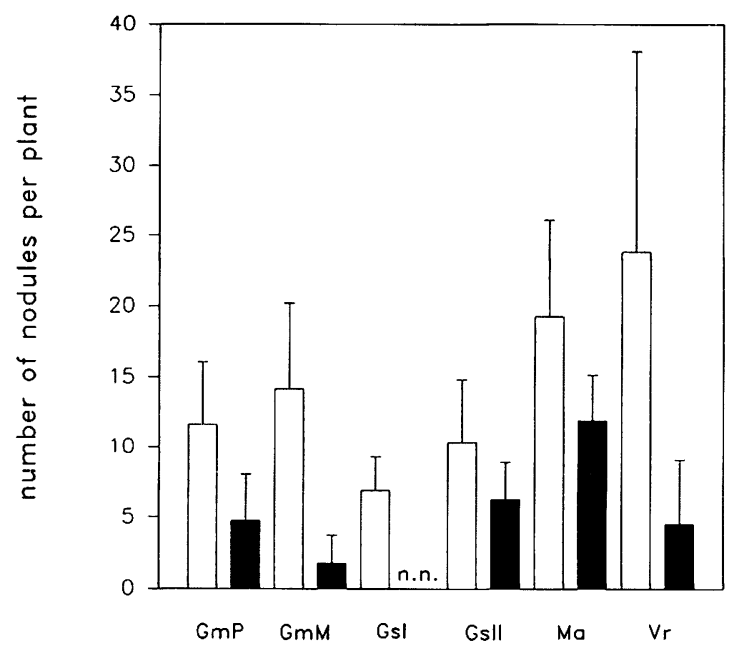

Fig. 2. Number of nodules per plant inoculated with $B$. japonicum 110 spc 4 (white bars) and $B$. japonicum $\triangle$ P22 (black bars). The data represent the average (with standard deviation) of three independent experiments (T-test, $n>17, p<0.05$ ). Differences between plants inoculated with $B$. japonicum $110 s p c 4$ and with B. japonicum $\triangle \mathrm{P} 22$ were significant for all host plants (GmP, Glycine max "Preston"; GmM, Glycine max "Maple Arrow"; GsI, Glycine soja PI 468397; GsII, Glycine soja PI 407287; Ma, Macroptilium atropurpureum; Vr, Vigna radiata; n.n., no nodules. The tissue protrusions of $G$. soja PI 468397 were not regarded as nodules in these experiments). 
Table I. Distribution of the nodules of different host plants after inoculation with B. japonicum 110 spc 4 and $B$. japonicum $\Delta \mathrm{P} 22$.

\begin{tabular}{lrrrr}
\hline & \multicolumn{2}{c}{$\begin{array}{l}\text { Rate of plants with nodules } \\
\text { on the main root in } \%\end{array}$} & \multicolumn{2}{c}{$\begin{array}{l}\text { Rate of nodules on the } \\
\text { main root in } \%\end{array}$} \\
& $110^{\mathrm{a}}$ & $\Delta \mathrm{P} 22^{\mathrm{b}}$ & $110^{\mathrm{a}}$ & $\Delta \mathrm{P} 22^{\mathrm{b}}$ \\
\hline Inoculum & & & & \\
Host plant & & & 46.7 & 28.4 \\
Glycine max cv. "Preston" & 100.0 & 52.4 & 32.4 & 17.3 \\
Glycine max cv. "Maple Arrow" & 92.1 & 18.0 & 50.0 & 0.0 \\
Glycine soja PI 468397 & 95.3 & 0.0 & 100.0 & 33.3 \\
Glycine soja PI 407287 & 100.0 & 68.8 & 26.9 & 11.4 \\
Macroptilium atropurpureum & 94.4 & 75.0 & 6.0 & 0.0 \\
Vigna radiata & 32.2 & 0.0 & & \\
\hline
\end{tabular}

a Bradyrhizobium japonicum 110 spc 4.

b Bradyrhizobium japonicum $\triangle \mathrm{P} 22$.

induced nodules of $V$. radiata, $G$. max "Maple Arrow", and G. soja PI 407287 reduced acetylene to a similar degree. Values obtained with the latter two cultivars were slightly increased. However, acetylene reduction of $G$. $\max$ "Preston" nodules infected with $B$. japonicum $\Delta \mathrm{P} 22$ exceeded that of wild type-infected nodules significantly (Fig. 3 ).

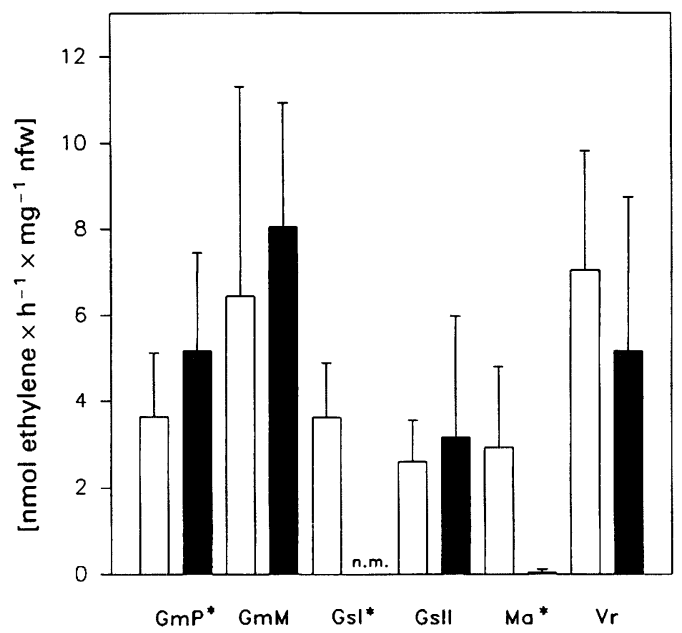

Fig. 3. Amount of reduced acetylene per mg nodule fresh weight ( $\mathrm{nfw}$ ) of root nodules infected with $B$. japonicum 110 spc 4 (white bars) and $B$. japonicum $\triangle \mathrm{P} 22$ (black bars). The data represent the average (with standard deviation) of three independent experiments (T-test, $n>11, p<0.05)$. Differences between plants inoculated with $B$. japonicum $110 s p c 4$ and with $B$. japonicum $\Delta \mathrm{P} 22$ were significant (marked by an asterisk) for Glycine max "Preston", Glycine soja PI 468397, and Macroptilium atropurpureum (GmP, Glycine max "Preston"; GmM, Glycine max "Maple Arrow" GsI, Glycine soja PI 468397; GsII, Glycine soja PI 407287; Ma, Macroptilium atropurpureum, Vr, Vigna radiata; n.m., no acetylene reduction measurable).
In contrast to this, acetylene reduction was hardly measurable with mutant-induced nodules of Macroptilium atropurpureum (Fig. 3). This observation could not be explained by the inability of the mutant bacteroids to fix nitrogen, since the identical mutant strain was fully effective in symbiosis with other host plants. However, the nodule cells of this host plant were infected by $B$. japonicum $\triangle \mathrm{P} 22$ less densely in most of the cases, as will be shown below. Acetylene was not reduced by the cell protrusions of G. soja PI 468397 (Fig. 3). This tissue was not infected and no bacteroids could be reisolated.

\section{Histological evidence for a disturbed infection process}

Apart from delayed onset and low frequency of nodulation, the infection process in Vigna radiata did not differ between inoculation with $B$. japonicum $\triangle \mathrm{P} 22$ or the wild type $B$. japonicum 110 spc 4 . The effective nodules induced by both strains showed the typical determinate nodule type with a comparable colonization of the central nodule tissue. Similar observations were made with G. soja PI 407287. However, in one of the examined nodules vacuoles were visible in infected cells $21 \mathrm{dpi}$ (Fig. 4 b), indicating a disturbed symbiotic interaction.

The cell protrusions, developed on $G$. soja PI468397 after inoculation with B. japonicum $\triangle$ P 22 were not infected. Growth of these tissues mostly arrested at a just visible state. With this host plant no infection proceeded as shown in Fig. $4 \mathrm{a}$, although remeristematization of cortex 

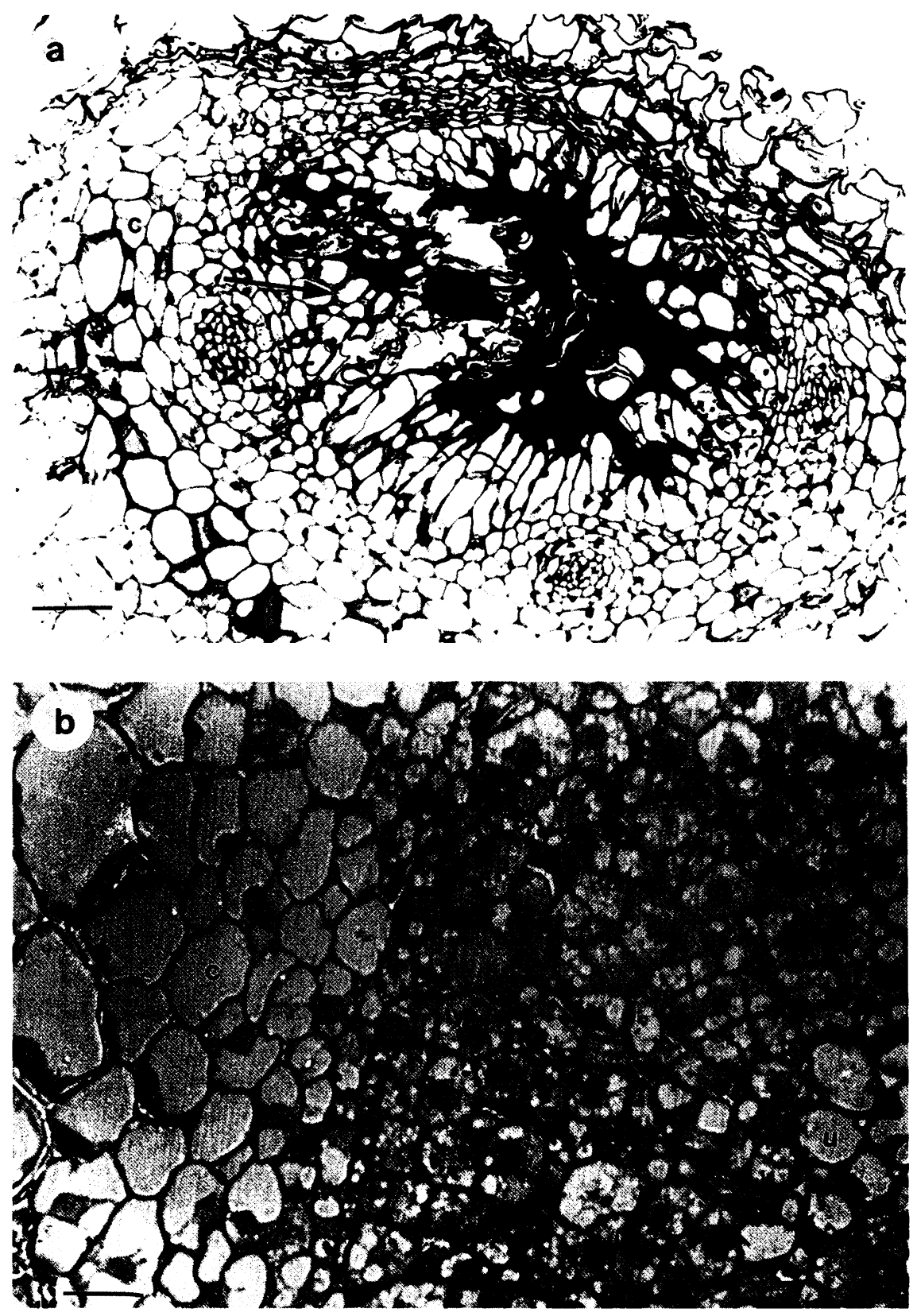

Fig. 4. Thin sections of nodules (21 dpi) of Glycine soja PI468397 (a) and Glycine soja PI 407287 (b) induced by $B$. japonicum $\triangle \mathrm{P} 22(\mathrm{ar}-$ row indicates cell wall thickening; iv, infected cell with vacuoles; u, uninfected cell; c, cortex cell; bar a: $35 \mu \mathrm{m}$, b: $7 \mu \mathrm{m})$.

cells was induced. However, the origin of these cell protrusions as a root nodule primordium was demonstrated by the arrangement of the tissue layers examined via cross-sectioning. The cells of the central tissue were unusually elongated. They were surrounded by a cortex tissue including vascular bundles and a ring of sclerenchymatic cells like infected determinate type nodules (Fig. $4 \mathrm{a}$ ).
At $21 \mathrm{dpi}$, the central tissue was already destroyed and filled with a readily dyeable mass of unknown composition. Some of the cell walls of adjacent cells were thickened (Fig. 4 a). The destroyed tissue and the surrounding tissues showed a blue autofluorescence after incitation by UV light indicating the presence of phenolic substances (Kosch, unpublished results). 

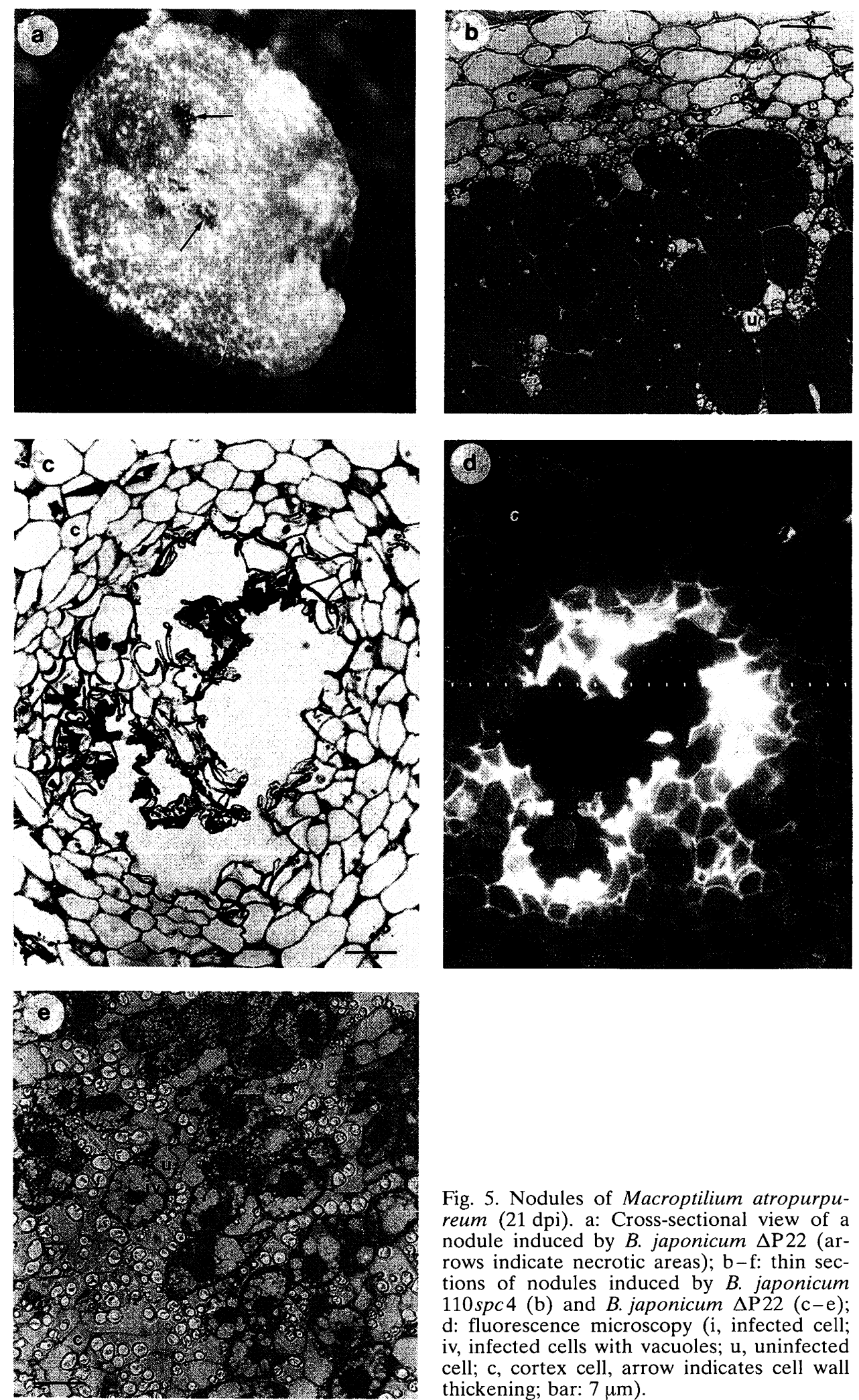

Fig. 5. Nodules of Macroptilium atropurpureum (21 dpi). a: Cross-sectional view of a nodule induced by $B$. japonicum $\Delta \mathrm{P} 22$ (arrows indicate necrotic areas); $\mathrm{b}-\mathrm{f}$ : thin sections of nodules induced by $B$. japonicum $110 s p c 4$ (b) and B. japonicum $\triangle \mathrm{P} 22(\mathrm{c}-\mathrm{e})$; $\mathrm{d}$ : fluorescence microscopy (i, infected cell; iv, infected cells with vacuoles; u, uninfected cell; c, cortex cell, arrow indicates cell wall thickening; bar: $7 \mu \mathrm{m}$ ). 
The symbiotic phenotype of $M$. atropurpureum inoculated with $B$. japonicum $\Delta \mathrm{P} 22$ is even more complex. On this host plant, $B$. japonicum $\Delta \mathrm{P} 22-$ induced nodules which resembled macroscopically and microscopically wild type-induced nodules with a red coloured central infected zone (Fig. $5 \mathrm{~b}$ ). However, these nodules represented less than $20 \%$ of the total amount of nodules. Other types of nodules with an only slightly red or uncoloured central tissue, indicating little or no leghemoglobin production were found on the same plants. Furthermore, in some of the nodules without any visible traces of leghemoglobin, necrotic areas evolved within the central tissue (Fig. $5 \mathrm{a}$ ). The cells of the central tissue were small compared to normal infected cells and no prominent nuclei were observed, demonstrating that the cells of these nodules had not undergone the transformation to polyploidy which normally takes place during the infection process (Verma and Long, 1983). The properties of the tissue of these areas impaired thin sectioning. As a consequence most of the tissue was torn out (Fig. $5 \mathrm{c}$ ). On the border of this tissue, cell wall thickening occurred (Fig. 5c), and a blue fluorescence was detected under UV light (Fig. 5d). However, most of the mutant-induced nodules of $M$. atropurpureum showed a slightly red colour. In these nodules the infected zone was not uniformly distributed via the central tissue, but restricted zones of infected tissue were separated by a greater part of uninfected tissue. In addition to this, large vacuoles in the infected cells were observed (Fig. 5e). Vacuolization was also detected in some mutant nodules with a uniformly distributed infected central tissue. The vacuolated cells were not densely packed with bacteroids like wild type cells (Fig. 5b). However, the vacuolated cells contained large nuclei (Fig. 5), indicating that the transformation to polyploidy had taken place. The different types of impairment in $M$. atropurpureum show that the variance of nodule development not only differs with the genotype of the host plant, but also within a single plant.

\section{Discussion}

The inoculation with the exopolysaccharide mutant B. japonicum $\Delta \mathrm{P} 22$ has several effects on the nodulation process of various host plants with a determinate nodule type. The first visible indi- cation is the belated appearance of the nodule primordia, which implies a delay of nodule development. This effect is further documented by the greater distance of the uppermost nodule from the root tip mark of mutant inoculated plants and the increased percentage of nodules induced at lateral roots compared to wild type inoculation. Rhizobial strains with a delay in nodulation are not as able to infect root hairs susceptible at the time of inoculation as the wild type, but root hairs which develop after some time of root growth which results in a greater distance in relation to the rtm.

For Macroptilium atropurpureum an enhanced level of phenylalanine ammonium lyase, which is involved in the plant defense was detected in seedling roots two days after infection with $B$. japonicum $\triangle \mathrm{P} 22$ (Kosch, unpublished results). The inoculation of G. max "Preston" with B. japonicum $\triangle \mathrm{P} 22$ leads to the accumulation of the phytoalexin glyceollin in the root exudate of seedlings 48-72 h after infection (Parniske et al., 1994). On the other hand, the resistance of $B$. japonicum 110 spc 4 towards glyceollin can be induced (Parniske et al., 1991; Kape et al., 1992). In this respect the delay of nodulation can possibly be regarded as a period of bacterial adaptation to induced plant defense responses.

The nodule number per plant is governed by the autoregulation system of the plant (CaetanoAnollés and Gresshoff, 1991). The arrest of the developing infection threads which show symptoms of a hypersensitive reaction is proposed to play a role in this respect within wild type-infected alfalfa plants (Vasse et al., 1993). The induced plant defense response after inoculation with B. japonicum $\triangle \mathrm{P} 22$ could block more successful infections. The extent of the effect depends on the degree of the induced plant defense which is manifested in the genotype of the host plant and the capability of the bacteria to cope with the specific defense mechanisms.

Parniske et al. (1994) showed that B. japonicum $\triangle$ P22 infects $G$. max "Preston" in a different mode of entry. Comparable macroscopical symptoms like disruption of the rhizodermis caused by cortical cell proliferations were also observed with G. max "Maple Arrow" (Kosch, unpublished results). However, the infection of these host plants and $V$. radiata finally leads to an effective nitrogen-fixing symbiosis, with a regularly infected 
zone, suggesting an only transient impairment of nodulation at an early stage of the infection process. Once the mutant bacteria have invaded the host cells further defense reactions have no influence on the effectiveness of the symbiosis. The specific nitrogenase activity of mutant-induced nodules of $G$. soja PI 407287 and the two cultivars of $G$. max even exceeds that of wild type-induced nodules. This increased specific nitrogenase activity could be based on a facilitated oxygen diffusion in these nodules as a result of the former impairment of the nodulation process. An enhanced $\mathrm{O}_{2}$ partial pressure leads to an increased nitrogenase activity since under normal physiological conditions $\mathrm{O}_{2}$ tension is suboptimal (Stripf and Werner, 1980; Layzell et al., 1990). As a consequence of the reduced number of nodules per plant, fewer nodules have to accomplish for the nitrogen demand of the host plant, a problem which is met by a higher effectiveness. This can not be achieved in $M$. atropurpureum and $G$. soja PI468397 where the colonization of the host cell by $B$. japonicum $\triangle \mathrm{P} 22$ is partly, respectively completely, blocked by the plant.

The severe disturbation of nodule development of $G$. soja PI 468397 was already described on the macroscopic level (Parniske et al., 1994). The disintegration of the central nodule tissue and the accumulation of phenolic substances suggest a strong defense response of the host plant during the infection process at the stage of nodule growth. This finally leads to the necrosis of the central nodule tissue. The severity of the effect can probably be seen in connection with the reduced compatibility of this plant genotype with the slow growing wild type strains of $B$. japonicum and the preference for fast growing strains (Keyser and Cregan, 1984; Parniske et al., 1990). Thus an already poorly adapted interaction can easier be unbalanced than a well-adapted symbiotic relationship represented by $G$. soja PI 407287 with slow growing strains. With this host plant, vacuolization of infected cells was only detected once. The later impairment of the symbiosis seemed to be rather an exception than the rule.

The interaction between $B$. japonicum $\Delta \mathrm{P} 22$ and $G$. soja PI 468397 is the first example of an Inf $^{-}$phenotype of a plant with a determinate nodule type in combination with an exopolysaccharide mutant and underlines the importance of this sur- face polysaccharide in symbiosis with these host plants. The phenotype resembles the situation of alfalfa nodules (indeterminate nodule type) induced by exo- mutants of Rhizobium meliloti. The induction of the synthesis of phenolic substances as precursors for a reinforcement of cell walls and the dying of tissue is similar to a plant defense response in form of a hypersensitive reaction (Niehaus et al., 1993).

The different nodule types of $M$. atropurpureum induced by $B$. japonicum $\triangle \mathrm{P} 22$ demonstrate that the influence on nodule development not only varies between different genotypes but also on a single plant. The reason for this is not yet understood. At the worst, the bacteria are not capable to invade the central nodule tissue and the tissue disintegrates. Possibly the necrotic spots represent the place of release of the bacteria from the infection threads and the altered surface structure provoked further defense responses at this stage. However, no histological proof for this hypothesis could be found. The cells of the central tissue of these nodules had not undergone the transformation to polyploid cells which normally takes place during the infection process (Verma and Long, 1983). The enhanced reaction could therefore be due to a failure of the bacteria to provoke essential physiological changes of the plant cells. In other nodules infected zones were not uniformly distributed via the central tissue but zones of infected tissue was separated by a greater part of uninfected tissue. In these nodules release from the infection thread occurred. However, the struggle of the bacteria to cope with the host defense responses seems to slow down the infection process and the growth of the bacteria. As a consequence, the bacteria were possibly not able to keep pace with the cell division activity of the plant, the distribution of the infected cells remained restricted to confined small areas. However, the vacuolated cells contained large nuclei indicating that the transformation to polyploidy had taken place. This raises the question whether polyploidy is a major prerequisite for cell invasion as already suggested by Verma and Long (1983).

Relying on the assumption that the disturbance of nodulation is caused by the induction of defense responses of the host plants, the velocity of the induction seems to determine the degree of the impairment. Although minor defense responses 
occurred with G. max "Maple Arrow" and "Preston" (Parniske et al., 1994) and G. soja PI 407287 at later stages of nodule development, the effectiveness of this symbiosis was not altered, and nitrogen could be fixed. The defense responses of G. soja PI 468397 and M. atropurpureum resulted in a more pronounced disturbation, up to an Inf $^{-}$phenotype implicating a lack of nitrogen supply for the host plant which finally leads to nitrogen deficiency symptoms. The former hypothesis that EPS is not essential for plants with determinate nodule type (Gray and Rolfe, 1990) has to be newly reflected. The genotype of plant species determines the reaction of the plant towards EPS mutants which can be very different as shown in this paper. Thus, the hitherto existing studies with EPS mutants may only represent combinations with partners where the disturbance of EPS had no major effects on the effectiveness of the symbiosis (Borthakur et al., 1986; Diebold and Noel, 1989; Hotter and Scott, 1991) as has been shown for Vigna radiata in combination with B. japonicum $\triangle \mathrm{P} 22$.

Bhuvaneswari T. V., Turgeon B. G. and Bauer W. D. (1980), Early events in the infection of soybean (Glycine max L. Merr.) by Rhizobium japonicum. I. Localization of infectible root cells. Plant Physiol. 66, $1027-1031$.

Borthakur D., Barber C. E., Lamb J. W., Daniels M. J., Downie J. A. and Johnston A. W. B. (1986), A mutation that blocks exopolysaccharide synthesis prevents nodulation of peas by Rhizobium leguminosarum but not of beans by $R$. phaseoli and is corrected by cloned DNA from Rhizobium or the phytopathogen Xanthomonas. Mol. Gen. Genet. 203, 320-323.

Caetano-Anollés G. and Gresshoff P. M. (1991), Plant genetic control of nodulation. Annu. Rev. Microbiol. 45, 345-382.

Diebold R. and Noel K. D. (1989), Rhizobium leguminosarum exopolysaccharide mutants: biochemical and genetic analyses and symbiotic behaviour on three hosts. J. Bacteriol. 171, $4821-4830$.

Finan T. M., Hirsch A. M., Leigh J. A., Johansen E., Kuldau G. A., Deegen S., Walker G. C. and Signer E. R. (1985), Symbiotic mutants of Rhizobium meliloti that uncouple plant from bacterial differentiation. Cell 40, 869-877.

Fisher R. F. and Long S. R. (1992), Rhizobium-plant signal exchange. Nature 357, 655-659.

Göttfert M. (1993), Regulation and function of rhizobial nodulation genes. FEMS Microbiol. Rev. 104, 39-64.

Gray J. X. and Rolfe B. G. (1990), Exopolysaccharide production in Rhizobium and its role in invasion. Mol. Microbiol. 4, 1425-1431.
The altered EPS structure of $B$. japonicum $\triangle \mathrm{P} 22$ leads to the reinforced induction of a plant defense while the wild type only induces minor reactions which do not impair the establishment of the symbiotic interaction (Schmidt et al., 1992). How wild type EPS is involved in the reduction of the defense responses and why different plants show a different degree of defense reaction still remain interesting questions to be solved. Further experiments with $B$. japonicum $\Delta \mathrm{P} 22$ will hopefully be helpful to answer these questions.

\section{Acknowledgements}

We thank Anja Klaucke for excellent technical assistance and Dr. David Weiss, Institut für Mikrobiologie, Marburg for critically reading the manuscript. This work was supported by the Deutsche Forschungsgemeinschaft (DFG) Bonn, Germany through the SFB 305: "Ökophysiologie: Verarbeitung von Umweltsignalen", and by a Human Frontiers Science Program (HFSP) Award (Strasbourg) to Prof. Dr. D. Werner.

Hotter G. S. and Scott D. B. (1991), Exopolysaccharide mutants of Rhizobium loti are fully effective on a determinate nodulating host but are ineffective on a indeterminate nodulating host. J. Bacteriol. 173, $851-859$.

Kape R., Parniske M., Brandt S. and Werner D. (1992), Isoliquiritigenin, a strong nod gene- and glyceollin resistance-inducing flavonoid from soybean root exudate. Appl. Environ. Microbiol. 58, 1705-1710.

Keyser H. H. and Cregan P. B. (1984), Interactions of selected Glycine soja Sieb. \& Zucc. genotypes with fast- and slow-growing soybean rhizobia. Crop Sci. 24, 1059-1062.

Koch B. and Evans H. J. (1966), Reduction of acetylene to ethylene by soybean root nodules. Plant Physiol. 41, 1748-1750.

Layzell D. B., Hunts S. and Palmer G. R. (1990), Mechanisms of nitrogenase inhibition in soybean nodules: pulse-modulated spectroscopy indicates that nitrogenase activity is limited by $\mathrm{O}_{2}$. Plant Physiol. 92, $1101-1107$.

Leigh J. A., Reed J. W., Hanks J. F., Hirsch A. M. and Walker G. C. (1987), Rhizobium meliloti mutants that fail to succinylate their Calcoflour-binding polysaccharide are defective in nodule invasion. Cell 51, 579-587.

Lerouge P., Roche P., Faucher C., Maillet F., Truchet G., Promé J. C. and Dénarié J. (1990), Symbiotic host specifity of Rhizobium meliloti is determined by a sulphated and acetylated glucosamine oligosaccharide signal. Nature 344, $781-784$. 
Müller P., Hynes M., Kapp D., Niehaus K. and Pühler A. (1988), Two classes of Rhizobium meliloti infection mutants differ in exopolysaccharide production and in co-inoculation properties with nodulation mutants. Mol. Gen. Genet. 211, 17-26.

Niehaus K., Kapp D. and Pühler A. (1993), Plant defence and delayed infection of alfalfa pseudonodules induced by an exopolysaccharide (EPSI)deficient Rhizobium meliloti mutant. Planta 190, 415-425.

Parniske M., Ahlborn B. and Werner D. (1991), Isoflavonoid-inducible resistance to the phytoalexin glyceollin in soybean rhizobia. J. Bacteriol. 173, 3432-3439.

Parniske M., Kosch K., Werner D. and Müller P. (1993), ExoB mutants of Bradyrhizobium japonicum with reduced competitiveness for nodulation of Glycine max. Mol. Plant Microbe Interact. 6, 99-106.

Parniske M., Schmidt P. E., Kosch K. and Müller P. (1994), Plant defense responses of host plants with determinate nodules induced by EPS-defective exoB mutants of Bradyrhizobium japonicum. Mol. Plant Microbe Interact., 631-638.

Parniske M., Zimmermann C., Cregan P. B. and Werner D. (1990), Hypersensitive reaction of nodule cells in the Glycine sp./Bradyrhizobium japonicum symbiosis occurs at the genotype-specific level. Bot. Acta 103, $143-148$.
Peters N. K., Frost J. W. and Long S. R. (1986), A plant flavone, luteolin, induces expression of Rhizobium meliloti nodulation genes. Science 233, 977-980.

Regensburger B. and Hennecke H. (1983), RNA polymerase from Rhizobium japonicum. Arch. Microbiol. 135, 103-109.

Schmidt P. E., Parniske M. and Werner D. (1992). Production of the phytoalexin glyceollin I by soybean roots in response to symbiotic and pathogenic infection. Bot. Acta 105, 18-25.

Stacey G., So J.-S., Roth L. E., Bhagya L. S. K. and Carlson R. W. (1991), A lipopolysaccharide mutant of Bradyrhizobium japonicum that uncouples plant from bacterial differentiation. Mol. Plant Microbe Interact 4, 332-340.

Stripf G. and Werner D. (1980), Development of discontinuous size classes of nodules of Glycine max. Z. Naturforsch. 35c, 776-782.

Vasse J., de Billy F. and Truchet G. (1993), Abortion of infection during the Rhizobium meliloti-alfalfa symbiotic interaction is accompanied by a hypersensitive reaction. Plant J. 4, 555-566.

Verma D. P. S. and Long S. (1983), The molecular biology of Rhizobium-legume symbiosis. Int. Rev. Cyt. Suppl. 14, 211-245.

Werner D., Wilcockson J. and Zimmermann E. (1975), Adsorption and selection of rhizobia with ion-exchange papers. Arch. Microbiol. 105, 27-32. 